\title{
Poetas en la frontera de México-Estados Unidos de América: Heriberto Yépez y Esther M. García
}

\author{
Poets on the United States-Mexico Border: \\ Heriberto Yépez and Esther M. García
}

Ignacio Ballester Pardo

Universidad de Alicante nachoballester7@gmail.com

ReSUMEN: La poesía mexicana se caracteriza en los últimos años por la descentralización de algunas prácticas literarias que tienen que ver con el conflicto producido en la frontera de México-EUA. Desde la obra de Heriberto Yépez, Por una poética antes del paleolítico y después de la propaganda (2000), hasta Esther M. García, con Mamá es un animal negro que va de largo por las alcobas blancas (2017), podemos estudiar

Palabras Clave:

telefísica;

fisión;

borderline;

feminicidio;

poética contextual;

descentralización. la fisión, la violencia, especialmente a las mujeres, la "telefísica" y el humor para criticar los límites que se cruzan entre múltiples poéticas y órganos de poder. En contacto con San Diego (California) y El Paso (Texas), la lírica que se ha publicado en las décadas recientes permite entender los problemas transfronterizos más allá de la convención.

KEYWORDS:

Telephysics;

Fission;

Borderline;

Feminicide;

Contextual Poetics;

Decentralization.
ABSTRACT: Mexican poetry in recent years is characterized by the decentralization of some literary practices that have to do with the conflict that occurs on the us-Mexico border. From the work of Heriberto Yépez, Por una poética antes del paleolítico y después de la propaganda (2000), to Esther M. García, with Mamá es un animal negro que va de largo por las alcobas blancas (2017), we can study fission, violence, especially against women, the "telephysics" and humor to criticize the boundaries that cross over multiple poetics and organs of power. In contact with San Diego (California) and El Paso (Texas), the lyric work that has been published in the last decades allows us to understand the cross-border problems beyond the convention.

25 septiembre 2018

10 enero 2019

Literatura Mexicana |XXXI-1 | 2020 | 99-131 | DOI: 10.19130/iifl.litmex.31.1.2020.1149 


\section{De Tijuana y Ciudad Juárez a San Diego y El Paso}

Entre Tijuana y Ciudad Juárez hay unos 1200 km por carretera. Son dos de las ciudades más representativas, no sólo del tráfico de México a Estados Unidos de América (EUA), sino de la cultura fronteriza que se da en el país con más hispanohablantes. Aunque Heriberto Yépez (Tijuana, Baja California, 1974) también trabaja en Berkeley (California) y pese a que Esther M. García (Ciudad Juárez, Chihuahua, 1987) radica actualmente en Saltillo (Coahuila de Zaragoza), las obras de ambos poetas permiten acercarnos a los límites de un género que en el siglo Xxı da cabida al conflicto, a lo experimental, a los feminicidios o a la maternidad: temas que en sus múltiples aristas colindan ya con la frontera de la tradición de la poesía mexicana contemporánea.

La ciudad mexicana en la que nació y vive Heriberto Yépez, Tijuana, colinda con San Diego, una de las más grandes de EUA. Dicho cruce fronterizo, en el extremo noroeste de México, es el más famoso de la tradición literaria y cinematográfica de ambos países. Por su parte, el lugar en el que pasó sus primeros años Esther M. García, Ciudad Juárez (Chihuahua), convive prácticamente con El Paso (Texas) y en el último lustro se ha convertido en uno de los territorios más hostiles de México. San Diego y El Paso albergan un buen número de poetas y docentes de México. En The University of California San Diego (UCSD), Heriberto Yépez fue profesor visitante del programa de maestría en escritura; mientras que The University of Texas at El Paso (UTEP) organiza el habitual Congreso de Literatura Mexicana Contemporánea y la reconocida Revista de Literatura Mexicana Contemporánea.

Una mirada global a EUA daría con los mexicanos Ignacio M. Sánchez Prado, José Ramón Ruisánchez Serra o Charo Hall, en algunos casos por las mejores condiciones profesionales que ofrece el país vecino. Más allá de las instituciones culturales del norte de México, entre las que descueIlan la Universidad Autónoma de Baja California (UABC), la Universidad Autónoma de Ciudad Juárez (UACJ) O, más al sureste, el Instituto Municipal de Cultura de Satillo en el que trabaja Esther M. García, Tijuana y Ciudad Juárez reúnen gran parte de las maquilas: fábricas al norte del país que en la frontera del siglo xx al xxI cambiaron el panorama, la seguridad, los 
derechos laborales y hasta la idiosincrasia de ciudades que se extendieron hasta topar con los límites de EUA, principal consumidor de esta producción en serie de electrodomésticos, ropa, etc.; tal como lo muestran Saul Landau y Sonia Angulo en el documental Maquila: A tale of two Mexicos (Maquila: Una historia de dos Méxicos) (2000) o Eva Sánchez Martín en "Feminicidio y maquila en Ciudad Juárez" (2007). Tijuana y Ciudad Juárez comparten así el auge y los problemas de industrias alrededor de las cuales cientos de mujeres han sido asesinadas debido a los cárteles de la droga, los proxenetas y las bandas criminales; aunque dichos problemas se extienden a toda la República mexicana (Palaversich 2012: 107). De esta manera, las plantas maquiladoras forman parte de la política neoliberal y de todo un proceso que encuentra su cumbre simbólica en 1994, con el North American Free Trade Agreement (NAFTA).

Christopher Domínguez Michael destaca los caracteres cervantinos que Yépez atribuye a los países fronterizos: "Estados Unidos es quijotesco, y México, sanchesco" (2009: en línea). Ahora bien, como en la obra de Cervantes, la frontera no impide en algunas ocasiones la sanchificación de don Quijote y la quijotización de Sancho; es decir, la "tijuanización" de San Diego y la "sandieguización" de Tijuana: "San Diego estaba volviéndose mexicana; de la misma manera que Tijuana, norteamericana. Todo estaba confundiéndose, la frontera estaba volviéndose una broma, una broma pesada, una broma enteramente macabra" (Yépez 2005c: 175). Tal fusión hecha fisión (Yépez 2012b) es inherente a Ciudad Juárez y El Paso. Y esto mismo ocurre con la Ciudad de México y Tijuana: "si ciertos tijuanólogos afirman que Tijuana se está achilangando (por la migración de sureños), otros, en cambio, se alarman porque México se está 'tijuanizando' (queriendo decir que se esta [sic] violentando, ya que, como todos sabemos, la violencia la inventó la Tía Juana)" (Yépez 2006: 83).

Con la santificación del violador Juan Soldado (Yépez 2006: 32-40) se instaura una ciudad contradictoria de por sí. A propósito de Al otro lado (2008), sobre la que diserta Silvia Ruzzi (2014), el también polémico Domínguez Michael considera que es "Tijuana [...] el sitio menos dispuesto a la americanización" (2009: en línea), mientras que la crítica Diana Palaversich señala el conocido espacio en el que se asienta la novela de Yépez: "Ciudad de Paso también evoca, desde su título, a otra ciudad 
emblemática del norte, Ciudad Juárez, que por su violencia excesiva - los feminicidios y posteriormente la narcoviolencia - le ha arrebatado a Tijuana el cetro de ciudad del crimen por excelencia, llegando a ser una de las urbes más peligrosas no sólo de México sino de todo el planeta" (2012: 107). Los tópicos que definen a las ciudades fronterizas como espacios inhabitables no responden sólo a la relación con EUA, sino también a la fisión que provoca la crítica desde la capital. La importancia de la frontera entre Texas y Chihuahua o Coahuila ya la estudió Gloria Anzaldúa en Borderlands / La Frontera ([1987] 2016) —trabajada a su vez por Belausteguigoitia (2009) desde la perspectiva feminista o Yépez (2017d) como descolonialismo fronterizo-, incidiendo en los límites con los que se encuentra la libertad sexual; presentes, como veremos, en los poemas de Yépez y García.

\section{La línea de la narrativa a la poesía}

La compleja historia de la actual frontera entre México y EUA (analizada por Revel 1984; Bustamante 1989; y Méndez, Rodríguez y López 2005) parte de la fundación del fuerte de San Agustín en 1565 por el almirante español Pedro Menéndez de Avilés. Como colonia española, posteriormente inglesa, y por un tiempo mexicana — desde la independencia del país que nos ocupa en 1810-, fue la intervención de EUA en México a mitad del siglo XIX, entre 1845 y 1847, el hecho que redujo el territorio mexicano a favor del estadounidense y detonó una serie de textos literarios con base histórica, tal como lo recoge Vicente Quirarte en Vergüenza de los héroes. Armas y letras de la guerra entre México y Estados Unidos (1999).

Desde principios del siglo XXI, cuando vuelven a agitarse los ánimos entre EUA y México — coincidiendo con el fin de la "dictadura perfecta": la derrota del Partido Revolucionario Institucional (PRI), tras setenta años de Gobierno, en palabras de Mario Vargas Llosa (Yépez 2006: 103)—, la narrativa es el género que mejor y más veces hereda los conflictos que cien años antes formaron el wéstern en la gran pantalla. Después de la cuentística de Eduardo Antonio Parra, destacan Luis Humberto Crosthwaite, con Estrella de la calle Sexta (2000) —entre otras—, la primera novela póstuma de Roberto Bolaño, 2666 (2004), Cristina Rivera Garza con La frontera 
más distante (2008) —allende los límites físicos—, el que mejor crítica tiene ahora mismo a propósito de este tema, Yuri Herrera y sus Señales que precederán al fin del mundo (2009), Valeria Luiselli en Los niños perdidos (2016), Juan Pablo Villalobos en Yo tuve un sueño (2018) o el propio Heriberto Yépez, como veremos, en la hibridez de su narrativa; metáfora, la de la hibridez, que resultará errónea para entender la frontera (Yépez 2005a: 45-58); pues, más que fusión, será una fisión. En la línea del tijuanense encontramos a Alejandro Zacarías (Yépez 2018a), Rafa Saavedra (Yépez 2005a: 95-117) —con quien desarrolló el blog como herramienta de escritura colectiva y digital (Saavedra 2012: 86-111) — y otros géneros recogidos, por ejemplo, a través de Javier Díaz Perucho (2004). Al contrario que García, Yépez continúa, según él mismo dice de Saavedra, "la función mítica del escritor norteño como outsider, marginal, alternativo, descentrado, antiliterario, periférico, barbárico, ausente en el mapa económico, mitad por el defederalismo, mitad porque así lo quiere él mismo" (Yépez 2005a: 87). Por el otro lado, Robert L. Jones, Jerome Rothenberg, Harry Polkinhorn o Mark Weiss Rothenberg serían estadounidenses que han querido formar parte de la literatura mexicana a través de traducciones y numerosas lecturas.

La frontera natural que da nombre a la película de Howard Hawks, Río Bravo (1959), establece no sólo un límite espacial y temporal cada vez más atractivo para la poesía mexicana contemporánea, sino que inspira una corriente que ha estudiado Israel Ramírez (2018). Te diría que fuéramos al río Bravo a llorar pero debes saber que ya no hay río ni llanto (2013), de Jorge Humberto Chávez (Ciudad Juárez, Chihuahua, 1959), marca nuevos rumbos para lo que tradicionalmente se ha considerado poesía social, denuncia meditada de la violencia, sin aspavientos o panfletos. Tales aspectos los desarrollarán Jesús Ramón Ibarra (Culiacán, Sinaloa, 1965) en Teoría de las pérdidas (2015) o Balam Rodrigo (Villa de Comaltitlán, Chiapas, 1974) en Marabunta (2017), Libro centroamericano de los muertos (2018) y un ensayo aún sin publicar que completará la estructura tripartita de esta obra del chiapaneco Rodrigo. Así pues, en los últimos años la frontera ha protagonizado libros que dejaron de ser poemas autónomos e independientes para formar poemarios con un hilo conductor y hasta trilogías. En este sentido también destaca la obra de otro conterráneo, Omar Pimien- 
ta (Tijuana, Baja California, 1978) y su poemario La Libertad: ciudad de paso (2006), donde teje la frontera con la violencia, el humor, el amor y la lectura de una ciudad que sigue el ejemplo de los también tijuanenses Francisco Morales o Luis Humberto Crosthwaite, entre otros (Palaversich 2012). Por otro lado, en Ciudad Juárez también destaca Rosario Sanmiguel (Ciudad Juárez, Chihuahua, 1954) con Under the Bridge/ Bajo el puente: Stories from the Border/ Relatos desde la frontera (2008); en poesía descuella el trabajo que recopila Uberto Stabile (Valencia, España, 1959) en Tan lejos de Dios. Poesía mexicana en la frontera norte (2010). Atendiendo a dichos aspectos, analizamos el significado de la frontera en las experiencias cotidianas y particulares que Yépez y García plantean en sus obras poéticas para evidenciar un problema común: el de la violencia en sus distintos niveles.

En el libro Enclave. Poéticas experimentales (2015) que coordina Rocío Cerón destaca Sound has no walls, de 2008-2009, una obra sobre la migración y la intervención de altavoces que forman una frontera entre México y Estados Unidos en Mexicali. ¿No podría ser este un precedente de lo que propone Homero Aridjis para augurar una respuesta a Donald Trump con un muro solar? (Aridjis 2011: 151). Desde la reciente exposición de Yépez en Tijuana (2017c) hasta las cárceles que separan a familias, el poeta (coincidiendo con Balam Rodrigo en los poemarios citados) reconoce en el libro que coordinan Édgar Cota y José Salvador Ruiz, En voz propia. In ther own voices. Entrevistas con narradores de la frontera México-Estados Unidos (2014): "Todo lo que escribo se refiere a la historia de mi vida. Toda mi vida se refiere a la historia de una infancia. Toda mi infancia se refiere a la historia de una familia. Toda mi familia se refiere a la historia de una migración. Toda esa migración se refiere a una historia de México" (Yépez 2014: 254).

Resulta cada vez mayor el número de poetas de México que viven y escriben la frontera con EUA: "El norte de México hace años que empezó a dar una interesante nómina de narradores y poetas que ya no migran al DF sino que empiezan a escribir y editar en el propio norte" (Stabile 2010: 13). Tijuana y San Diego o Ciudad Juárez y El Paso son ejemplos de este oxímoron que es la cercanía fronteriza a la que alude la coahuilense Esther M. García. Asimismo, pensamos en Cristina Rivera Garza (Mata- 
moros, Tamaulipas, 1964), Dolores Dorantes (Córdoba, Veracruz, 1973), Manuel Iris (Campeche, 1983) o Stephanie Alcantar (Illinois, EUA, 1990) como poetas de México en EUA. La veracruzana Dorantes se vio obligada a abandonar México en 2011 e irse a vivir a EUA por las amenazas que recibió debido a su labor feminista (Ballester 2018b). Así lo expresa en Estilo (2011): "somos adolescentes armadas cruzando la frontera" (18). En su caso, el campechano Iris — reciente Cincinnati's New Poet Laureate y mencionado junto a Octavio Paz en la telenovela Por amar sin ley- escribió el poema "Soy de aquí" (publicado inicialmente en su Facebook) tras la imposición que buena parte de la población mexicana en EUA sufrió por el gobierno de Donald Trump para no salir del país estadounidense y no compartir ciertos contenidos en redes sociales. Contra la tele-visión, "es imposible quedarse, aunque te quedes" (Iris 2017: en línea).

La línea que separa y une a ambos países representará en la lírica mexicana el paso de la metafísica a la "telefísica" (Yépez 2008b), como veremos, del más allá (EUA) a lo cercano (México). El cambio de dicho proceso lo defiende Heriberto Yépez de manera explícita tanto en sus poemarios Por una poética antes del paleolítico y después de la propaganda (2000), El órgano de la risa (2008) o El libro de lo Post-Poético (2012) como en sus ensayos Made in Tijuana (2005), El imperio de la neomemoria (2007) o Contra la Tele-visión (2008) y lo continúa Esther M. García en la narratividad y en la visualidad de su poética, desde La doncella negra (2010) y Sicarii ([2013] 2014) a Bitácora de mujeres extrañas (2014) y Mamá es un animal negro que va de largo por las alcobas blancas (2017).

\section{Del paleolítico a la propaganda}

En ese año inaugural para el tercer milenio, en el paso del paleolítico (pudiendo ser considerado como la lectura lineal de una utópica y errática fusión de países limítrofes) a la propaganda (escritura digital que produce una fisión entre diversos géneros políticos y literarios), Letras Libres decide dedicar su número 17 (mayo, 2000) al tema que nos ocupa. Lo hace con el título "Vida en la frontera" y cuenta con trabajos sobre Tijuana de Juan ViIloro — "salpicado de inexactitudes" (Yépez 2006: 75)—o de José Emilio Pacheco sobre poesía. Otras revistas, a principios del siglo XXI, coordina- 
ron números especiales sobre el tema de la frontera que, con la llegada de Felipe Calderón al gobierno en 2006 y la militarización del país, pasó del famoso "laboratorio de la posmodernidad" (García Canclini 1989: 298) —aunque el mismo García Canclini reconoce recientemente que se ha convertido ya "en un laboratorio de la desintegración social y política de México como consecuencia de una ingobernabilidad cultivada" (Montezemolo 2009) — a la temida ciudad del crimen (Palaversich 2012: 100-101). La popularización de internet posibilita que un estudio sobre la frontera publicado en una de las revistas más importantes de México difunda una serie de tópicos que se crean desde las élites intelectuales y se reconocen directamente en el público lector: "Es la industria consumocultural lo que determina la fronteridad de un sitio, no el territorio. Tijuana no es la frontera más cruzada del mundo, es el internet" (Yépez 2006: 89).

Por una poética antes del paleolítico y después de la propaganda (2000) es el libro de Heriberto Yépez que asienta la preocupación por la frontera en su poesía y en lo que se irá publicando en México. Se estructura en cinco series: "contrapoemas", la que da nombre al libro, "Laboratorio de El libro maya de los muertos", "Obranzas de la etnopenínsula" y "Mínima antología gringa". A la manera de Nicanor Parra, el post-transfronterizo se opone a la poesía hermética o ensimismada de buena parte de la tradición mexicana y estadounidense, describiendo un paisaje que contamina el capitalismo con plásticos que vienen de China o despojos de lo que nos dicen que es la sociedad más marginal: "pervertidos sexuales, vendedores de mercancías / robadas, carteristas, asalta indígenas y turistas" (11). Recordemos que el paisaje y el paisanaje de Tijuana, conocida como la "Tercera Nación" por las apropiaciones que se tratan de imponer externamente a México y EUA, contrastan con los de San Diego, a poco más de treinta kilómetros. "La tercera nación se construye como un palimpsesto fronterizo formado a partir de textos inscritos en los espacios urbanos, así como en los ámbitos culturales legitimados e independientes" (Valenzuela ápud Moraña 2008: 30). En el borde fronterizo, "la malla también es espacio para la resistencia y la denuncia donde se levanta una enorme hilera de cruces que simbolizan a los migrantes muertos" (30). Las placas que EUA utilizó en la guerra contra Irak sirven ahora de muro. Llantas y demás piezas sueltas forman habitáculos para las zonas mal avenidas de Tijuana, 
sin embargo, continúa el poemario de Yépez, "en el centro de San Diego / no hay una sola casucha / una tienda de mala muerte" (17). Pese a Yépez, parece que "[l]a ignominiosa chatarra cumple una función de propaganda; anticipa los horrores que pueden sufrir los temerarios" (Villoro 2000). Recientemente, a propósito de estos residuos, Yépez establece un tránsito del Hibridismo a las Rudologías (2018b).

La oralidad, con la primera persona, da testimonio de escenas cotidianas, urbanas, valiéndose muchas veces del tradicional metro español, en ocho sílabas, y en ocasiones de asonancias y de rimas internas que podrían acercar estos versos a la música, al rap. El tópico de la ciudad estancada que se enfrenta al avance del capitalismo se enriquece con juegos enunciativos e irónicos donde diversas voces (algunas en cursivas) recrean un diálogo en poemas breves que cierran con otra voz que responde:

\author{
¿qué haces ahí apestando \\ tirado en la banqueta \\ viviendo \\ en la nación más rica \\ del planeta? \\ Rascándome los huevos \\ viendo \\ rascacielos
}

(Yépez 2000: 18)

Los edificios altísimos y ostentosos (seguramente llenos de oficinas con gente que trabaja desde temprano por la subida del dólar) contrastan nuevamente con el teporocho (a veces homeless) al que le pica lo más vil mientras pide algún peso que le permita llevarse a la boca un perrito caliente o, en el mejor de los casos, "una torta rancia" (21). De esta manera, la diferencia de los verbos en gerundio ("viviendo" y "viendo") es más que una sílaba repetitiva: se privilegia la imagen, el sentido de la vista, la "telefísica". En esta continua tragicomedia mexicana (que, a pesar de Yépez, dibujara José Agustín para la segunda mitad del siglo xx), la imagen se contrapone más adelante, pues "gringos Ilevados por bilingües taxistas / pierden su American Express / en un masaje a los huevos / que cuesta 20 pesos / en la Calle Coahuila" (37). Entre el trabajo artesanal de la tradición y el "emprendedurismo" o startup del siglo xxl, la poesía requiere un nue- 
vo lenguaje que simple y llanamente profundice en los problemas y las diferencias sociales allende las fronteras: "Esta represión lleva a que en la ciudad el hablante se sitúe en un espacio de marginalidad respecto a los 'otros' con los que se ve forzado a convivir por la existencia de la frontera" (Baeza 2012: 27). El flâneur de Charles Baudelaire o Walter Benjamin (Palaversich 2002) es ahora un "peatonauta" (como diría Ramón Castillo) y viaja en autobús al centro de las ciudades, pasando por la sangrada periferia: "quienes llegan a la central / más bien parece / que no se van / llegan para quedarse" (Yépez 2000: 20). En otras ocasiones, la expresión popular pone fin a una caricatura del monólogo interior en el que las dudas de si migrar o no, además de las drogas, le pueden hacer a uno perder la cabeza: "allá en el norte / no te vayas a nortear" (30). En dicho sentido, para no desorientarnos, las referencias espaciales son reconocibles, pues suelen aludir a lugares emblemáticos, en este caso, de Tijuana; como es "la calle Coahuila / [...] polleros norteados / afónicos pordioseros / encueratrices peludas de los sobacos" (37). Yépez reivindica así la idiosincrasia de una ciudad donde se suceden personajes o términos que enriquecen la lengua y la cultura como "polleros" o "encueratrices"; gracias al Diccionario de mexicanismos (2010) sabemos que se refiere a "supran. pop/coloq. Persona que se dedica a llevar y pasar ilegalmente personas a Estados Unidos" (477) y a "coloq/despect/p.u. Mujer que se quita la ropa en público, particularmente en escenarios o películas" (203), respectivamente. Con el mismo significado de pollero, el "coyote" (152) responde así a "la migra" y sus anglicismos: "en todas partes queriendo pasarte / la línea / illegaly / iqué nos puedes decir al respecto!: // “¡Yo! / Si yo nomás / me ando paseando / [...] por las tierras / de los abuelos naguales" (Yépez 2000: 45). El término inglés contrasta con la zona de antepasados naguales. El lenguaje del imperio contra las lenguas originarias. El laboratorio de poesía expandida que ha organizado Rocío Cerón en los últimos años para la literatura experimental ya lo cultivaba Yépez para recrear el mensaje de las culturas originarias de México "a partir de la traducción que el exegeta Paul Arnold hizo del 'Código París' redactado por los sacerdotes-poetas mayas" (95). Antes, en la parte central de este libro, el poeta ofrece un subapartado llamado "Contextos" en el que estamos ante, como reza el pie de la primera imagen: 
Fotografías de POEMAS QUE EL AUTOR INSTALÓ EN PANELES DE ACRílICO sobre postes, señales, semáforos y rejas en el centro y la línea internacional de la ciudad de Tijuana, como parte de un proyecto visual de poesía bilingüe en la vía pública: "Poética contextual" (67).

Efectivamente, la imagen que abre el proyecto impreso "Poética contextual" muestra a un norteño de espaldas con un cartel a la altura de su famoso sombrero. El texto ("ESTA / FRONTERA / YA SE PASÓ / DE LA RAYA"), instalado por el propio Yépez, se compone de letras blancas en un panel negro de no más de medio metro cuadrado. El espacio, el hueco, el vacío entre "LA" Y "RAYA", coincide causalmente con el poste que sostiene éste y demás poemas breves; de manera que, como el nombre del proyecto indica, el significado de la performance no se completa sin la relación de la poesía con su contexto, fotografiado e impreso. Otros mensajes en inglés se sostienen por numerosos postes, horizontales o verticales, que forman un límite físico, una valla, para la frontera que paradójicamente te recibe de este modo: "WELCOME TO THE CITY [...]" (68). La línea horizontal, alegóricamente, tacha el texto como borradura. Se trata, según vimos en otro trabajo (Ballester y Higashi 2017), del discurso obliterado que cada vez más las tecnologías de composición textual facilitan para la edición de un poemario y su puesta en escena, de la (ya reiterada) búsqueda de la originalidad y del miedo ante el hecho creativo (en este caso, también vivencial); pues el límite político entre estados o países puede definirse como: "ZONA / DE / DERRUMBES / EXISTENCIALES" (70). La técnica de Yépez, fotografiar textos que cobran un significado particular en Tijuana, encontrará nuevas posibilidades con redes sociales como Instagram (Yépez 2017a), tal como lo hemos estudiado (Ballester [en prensa]) a propósito de las otras lecturas del tercer milenio, en las cuales Esther M. García desarrollará en Sicarii una técnica que ahondará en los límites entre la razón y la cordura a partir de láminas de estudio psiquiátrico de personajes que han sufrido la violencia desde la infancia. Los tipos de fronteras (mentales, temporales, genéricas, visuales) se superponen a las espaciales en poetas digitales que desarrollan analogías del espacio y de las cartografías de poder (Ledesma 2016: 182). 
La sección que lleva por título el del libro Por una poética antes del paleolítico y después de la propaganda enumera breves aforismos o sentencias sobre el oficio poético, de manera que complementaría el trabajo de Carmen Alemany en Artes poéticas mexicanas (de los Contemporáneos a la actualidad) (2015). Pese a sostener que "[l]a 'poética' no se 'ocupa' de la poesía. Tampoco la poesía" (2000: 91), Yépez, entre las 175 disquisiciones sobre la poesía desde la poesía, también ofrece el arte poética de la frontera que se basa fundamentalmente en dos preceptos: el lenguaje y la ciudad. Por un lado, destaca la evolución del habla que ya hemos comentado: tanto Esther M. García en La doncella negra o Bitácora de mujeres extrañas, mediante los testimonios que comentaremos de mujeres reales que sufrieron la violencia en el norte de México, como Balam Rodrigo con la apropiación y reescritura (a la manera de Yépez y los mayas) de la Brevísima relación de la destrucción de las Indias de fray Bartolomé de las Casas (1552) y su Libro centroamericano de los muertos (2018), ejemplo de las muertes que provocan las fronteras, en este caso, desde el paso de Centroamérica a Estados Unidos a través de México. Por otro lado, en cuanto a la ciudad, destaca la lectura pública de poemas que explican los límites del espacio urbano en las propias fronteras de la comunidad.

Heriberto Yépez y Esther M. García son coherentes con sus poéticas (vinculadas en buena parte de sus propuestas), con sus obras narrativas y con sus ensayos. El tijuanense concluye Por una poética antes del paleolítico y después de la propaganda con las series "Obranzas de la etnopenínsula" y "Mínima antología gringa", donde "da forma de poema" a distintos testimonios orales y escritos de su tierra mexicana, por un lado, y de la tradición en lengua inglesa, por otro: "Así es la historia de cómo se / perdieron los ejidos / y de cómo los viejos indios / se fueron para Estados Unidos" (2000: 108); mientras que la chihuahuense dará voz a las trabajadoras de las maquilas que son asesinadas. Y lo hará mediante una serie de poemas de máscara — definitorios de la poesía mexicana (Higashi 2015: 354-355) — que abren Bitácora de mujeres extrañas.

La propaganda surte efecto. "Todos somos Bartleby. Copistas, clandestinos propagandistas del capitalismo sin salida" (Yépez 2007a: 47). En cuanto al gobierno y la masificación de la información: "La cultura mexicana popular-mediática vanagloria su pensamiento reaccionario desple- 
gando todos los significantes que indican que lo popular es lo verdadero (¡la Neta!) en cada telenovela, parodia política, chiste, personajazo, mueca o refrán. ¡Como si todo ello tuviera necesidad de propaganda! Pues se simula que no ha llegado al poder, que apenas está a punto de tomarlo" (Yépez 2008b: 38). No obstante, el tijuanense se contradice más allá del verso, pues en el resto de su obra emplea ese mismo lenguaje popular que critica (entendemos ahora que para caricaturizarlo). "La Neta, como parte del populismo mass-co-mediático, muestra la indisoluble unión de lo fresa y lo vulgar, lo high y lo chalán, lo quijótico y lo sánchico; muestra nuestra versión cultural de lo que abstractamente hemos Ilamado el cocontrol, el poder-peón" (56). Al igual que Yépez, García también parodia la pronunciación inglesa y callejera que se mezcla con el español. En su primer poemario, La doncella negra, la chihuahuense ofrece dos veces el poema "[l love the streets]" donde se habla de "ai lov de estrits" (2010: 41 y 66): bien por error en la edición, bien por evidenciar la producción en serie de las maquilas.

En este sentido, Yépez continúa deconstruyendo la propaganda de la frontera en El órgano de la risa (2008) a través de escenas teatrales que recuperan nuevamente el pasado y el presente indígenas, como en la serie de poemas del "Canto del transmaíz" que recrea el altar precolombino de calaveras, ahora, en "(Tzompantli de plástico)" (2008a: 35) —he aquí, más que la transculturación, el choque al extremo que continuará García en "Plastic Cows" (2014b: 78) con una mirada ecocrítica (Yépez 2017d) que se acerca al compromiso de José Emilio Pacheco y Homero Aridjis (Ballester 2018a)—; o la "Epístola del manco", previa a una "Autobiografía" en la que Cervantes (tan recurrente en la alegoría de don Quijote y Sancho) recuerda a las muertas de Juárez, esas otras Nadie (Yépez 2005a: 148) por la imposibilidad de armar en palabras la vida de quien muere desmembrada, pues "no abundan las obras redactadas por pedazos de carne" (2008a: 53), empresa que logrará llevar a cabo Diana del Ángel en Procesos de la noche (2017) con el rostro de Julio César Mondragón.

El libro de lo Post-Poético (2012) se abre con "Preparativos para el cru-

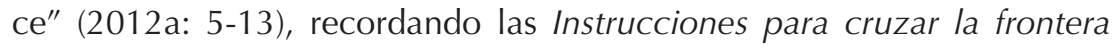
([2002] 2011) de Luis Humberto Crosthwaite (Arenas 2005), con versos que vuelven a sangrar y se desplazan: 
Así que a partir de cierto punto y aparte, no me deterioré como correspondía.

A partir de entonces, sobrevivo

en una especie

de pausa pétrea,

buffer zone bufón, entretanto,

nepantla

o como quiera llamársele a esta tregua.

Estoy atorado

entre este y el otro lado.

Y cuando mi salto está listo:

la raya se desplaza

(Yépez 2012a: 6).

Como es habitual en la poética de Yépez, la semántica va de la mano de los recursos tipográficos. En este caso, la raya, la línea, la frontera, cercana al bordo (cauce y muro) que canaliza el agua que fluye (y que encierra algunas de las muertes más trágicas de los últimos años) se aleja por el sangrado. Y es que el bordo, el dique junto al río Bravo o río Grande, separa México y EuA hasta El Paso. Los dos versos quedan ligeramente sin contacto por la grieta que une y separa la falla (2007b). En tal línea, Alejandro Aura eleva lo absurdo en su poema "Narcos" para explicarnos algo más profundo que tiene que ver con los problemas de México: "Ese avión es de narcos: / cortó dos líneas / en la pizarra del cielo / los ángeles / esnifarán a gusto" (45); en la tónica de Esther M. García y La doncella negra (2010): "Padre: / Soy una línea quebrada / crack crack crack" (30). Por su parte, Carlos Ramírez Vuelvas emplea en Los Contradioses (Premio Nacional de Poesía Tijuana 2014) la sátira para denunciar el crimen en la frontera entre EUA y México, con el significado de "hacer saltar con violencia, especialmente por medio de una sustancia explosiva" (DRAE) o "robar" (Company: 625) que tiene el verbo "vuela": "-Dicen que en mi país el que no corre, vuela" (Ramírez: 9). Tal humor es necesario para la tragicomedia, para los contrastes, para desacralizar el género que nos ocupa a través de la recuperación de expresiones populares con mínimos cambios contextuales y léxicos, pues: "Todos / los / caminos / Ilevan / a / broma" (Yépez 
2012a: 40). Esa raya, blanca y abstracta que une no generaciones sino constelaciones (Higashi 2015) en Alejandro Aura (1944-2008) o Carlos Ramírez Vuelvas (Colima, 1981) se liga con la droga que cruza ese límite entre la banda y el consumidor. Así continúa el poema de Yépez: "Y cuando la raya se ha distanciado lo suficiente / para que decida olvidarme de cruzarla, / la línea condenada / me tienta / deslizándose hasta mi mejilla. / Aspiro la raya de una jalada. /Y aparece de inmediato otra línea paralela. / Aspiro y aspiro: / las líneas jamás se terminan" (2012a: 7). Debido a los medios que ofrecen ahora altavoces y herramientas más eficaces para la denuncia, el panfleto o la crítica política, a través de la sátira, el desdoblamiento y la oralidad de un lenguaje cercano mas plagado de alegorías que se vinculan, como veíamos anteriormente, con al arte callejero o el rap, lo que tradicionalmente se ha considerado poesía social evoluciona a una dimensión cívica de la poesía mexicana contemporánea cuyo máximo representante sería Óscar de Pablo (Cuernavaca, Morelos, 1979) con El baile de las condiciones (2011) o De la materia en forma de sonido (2015).

El tono de El órgano de la risa y El libro de lo Post-Poético de Yépez es común en los demás poemarios que se publican en una época en la que el conflicto con la frontera entre ricos y pobres, con la desigualdad en medio de dos países, con una máxima que recuerda al famoso cuento de Mario Benedetti, "Su amor no era sencillo" (1989), donde la agorafobia (de EUA) y la claustrofobia (de México) implican que la vida únicamente crezca en El Paso, el lugar más seguro si acontece un sismo: "Soy un hombre de frontera. Mi obsesión es el umbral" (Yépez 2012a: 13).

Por estos años, en 2012, de nuevo recordando a Parra, Yépez cruza la frontera del verso y se aleja de la poesía convencional, tal como lo muestra de manera explícita - y con asonancias que cualquier poeta evitaríaen el texto que da nombre a El libro de lo Post-Poético: “¿Leporinos míos! A este despertar se debe lo antipoético / ( $\mathrm{y}$ —agrego- se debe también el fin de las estructuras / históricas del verso)" (2012a: 17). Se despide del género literario por la propaganda: "No quiero hacer poesía. / [...] Lo que quiero es un nuevo grito (ya lo dije / Lo que quiero es otro silencio" (21). Es más: "Sé que estoy cerca. Todo lo que siento se parece / A aquello que siento cuando cruzo la frontera. // Ahí están los guardias (son invisibles / Ahí están los límites (históricos, naturalizados, operantes / Ahí 
están los muros (más que triples" (22). Sin embargo, un lustro después publica Transnational Battle Field (2017), pero lo editan en EUA y en inglés. Además, como hiciera Juan Luis Martínez en la cubierta de su poemario La nueva novela (1977), el tijuanense tacha su nombre: Heriberto Yépez. Y es que la frontera ha llegado a la poesía en forma de tachadura: "to monstrueso es lo que vale / ser mostrado. / Monstruosa ta poesía" (Yépez 2012a: 35). La Bestia, el diablo, la Monstruosa, sobrevive a la raya que se superpone en el nombre del mismo autor de Transnational Battle Field, marcando así una técnica recurrente en la poesía mexicana contemporánea: la del discurso obliterado que ya vimos con su primer libro Por una poética antes del paleolítico y después de la propaganda: "Y es por esta telar razón / que desde hace mucho / tiempo / (yo) / habito / este / lado / del / absurdo" (Yépez 2012a: 66). Tales propuestas performativas cristalizan en actos visuales de arte fronterizo en la poética experimental transnacional de la que Yépez forma parte hasta su reciente Una Historia del Arte of Border Art (2017c: en línea).

\section{La realidad de la ficción, la "telefísica" y otra madre patria}

A través de las distintas formas de enunciación que van del poema de máscara al heterónimo, al coloquio, al monólogo dramático o al testimonio como apropiación o retórica textual de la poesía mexicana contemporánea, Esther M. García se pone en la piel de las maquiladoras que mueren después de trabajar en negro más de doce horas, dejando a la familia huérfana, y da voz a quienes sufren la violencia de sus maridos y hasta de sus hijos; denuncia, en definitiva, el feminicidio como una de las consecuencias de la violenta frontera entre México y EUA. A tales maquiladoras también se dirige Yépez en A.B.U.R.T.O. (2005c), en relación con los televisores que se fabrican en la urbe fronteriza que es Ciudad Juárez o, en este caso, la que vio nacer al poeta: "Durante esa época la mayoría de los monitores del mundo eran escupidos desde Tijuana (maquilandia), como en $[\ldots]$ una gran plaga de aparatos $[. .$.$] desde la frontera méxico-$ americana hasta caer, en fascinante fall-out, en sus distintos destinos finales" (2005c: 37). El trabajo aparentemente nimio y anónimo de quienes empacan las pantallas produce un aparato que será el núcleo de muchos 
de los hogares (como vemos en su ensayo Contra la Tele-visión, de la metafísica a la "telefísica"), hasta el punto de ser la base de los nuevos modos de lectura digital que facilitan los archivos abiertos, disponibles en la red, de Yépez y García.

Como adelantábamos, Esther M. García ofrece en su poética varios recursos para la enunciación y la visibilización de la violencia, especialmente de mujeres y madres en contacto con los distintos tipos de frontera. La reflexión sobre las relaciones entre México y EUA no es tan evidente como en los trabajos de Heriberto Yépez, pero plantea un registro que incide en la historicidad reciente y en la autobiografía de un género literario que, con su obra, se encuentra a caballo entre lo que ocurrió y lo que podrá suceder. García se aleja del humor y el tono decadente y ácido para profundizar en casos familiares que nos hacen ver de lejos lo cercano, y viceversa, así como para crear una imagen necesaria y reivindicativa de la mujer como origen de una atmósfera, por momentos, surreal. Bitácora de mujeres extrañas (2014) recoge de La doncella negra (2010) y Sicarii ([2013] 2014) los tonos oscuros y la voz narrativa de una poética que culmina, de momento, en Mamá es un animal negro que va de largo por las alcobas blancas (2017).

La doncella negra parte de la frontera temporal para recurrir a la infancia, cercana al contexto autobiográfico de la autora, y empatizar con el que será el protagonista de su siguiente poemario, Sicarii. El poema "[Demiurgos]", en el ámbito doméstico que se toca con lo fantástico, explica el origen de la voz narrativa (que convive con el inglés) a través de una arcilla que se amasa con los desechos: "Mi madre ha juntado arena roja del desierto de / Dead woman's city ${ }^{46}$ / y mi padre ha traído los huesos / frágiles" (2010: 12). Más adelante, "[El plomo y yo]", dedicado "A los niños olvidados en Torreón" (20), atiende a la contaminación de las fábricas (donde el padre murió de cáncer): "El agua veneno inunda las cañerías / se sirve a diario a la hora de comer" (21). El compromiso ecocrítico que veíamos con Yépez se recupera en García con un río que aún es más

46 Así, Dead Woman's City (Ediciones Bison, 2019), se titula el poemario sobre la frontera que Esther M. García acaba de publicar; disponible en la red: <https://drive.google. com/file/d/1X2zcsohRBuNk9xfqk6tl6ePYdTGqaR5O/view?fbclid=IwAR3xvzBM9g opxXX5Qf3KvuDRk9vf9p7jWOla8gxKXB-jKBXLEJJTjbaieM>. 
Bravo. Y es en la serie de poemas que da nombre al libro, "La doncella negra", donde se asienta la tríada que caracteriza a la poeta de Saltillo en torno a la frontera: la mixtura de diversas realidades-ficciones, la alegoría evolutiva del tijuanense y la criatura materna que devendrá animal negro. En una página que cambia de sentido, al horizontal, leemos:

\section{MADRE \\ ¿Podrías dejar de ver le tele y voltear a verme?}

(García 2010: 29)

En la separación de la madre y la hija, entre quien escribe el poema y quien lo lee, entre lo convencional y la ruptura del orden establecido, se sitúa el interrogante que planteaba Yépez. Con sorna, el tijuanense manifestaba en A.B.U.R.T.O.: "Volverse humano es un matricidio" (18). Y es que el título de esta novela con tintes teatrales, ensayísticos e incluso poéticos es un juego de palabras de las siglas que presiden importantes empresas estadounidenses o la paronomasia de la muerte voluntaria o accidental del feto: aborto (2005c: 40). La placenta, la protección materna, la educación ante la barbarie y la poesía tras el crimen son una frontera muy necesaria que consolida Esther M. García. A través de imágenes de televisión o de ordenadores personales, la realidad y la ficción forman parte de la cotidiana existencia de una comunidad, la mexicana, la estadounidense o la mexicoestadounidense. La televisión o el monitor también simboliza ese aparato que fabrican las maquiladoras en el borde de México y exportan a EUA.

Recordemos el tránsito de la metafísica a la "telefísica" que establece Yépez en Contra la Tele-visión: un ensayo antiestelar: "La metafísica postula que hay que ir más allá de este mundo para encontrar la 'realidad', la 'verdad' o la 'esencia'; la telefísica, en cambio, postula que hay que buscar todo ello 'más allá' pero dentro de 'este' mundo" (2008b: 11). "La frontera no está afuera. La frontera está adentro, es una especie de raya que divide los dos lados de nosotros mismos, [...]. Para cruzar la frontera, Mario no necesita ningún documento. Le basta pensar y ya está del otro lado de la garita" (Yépez 2005c: 182). Existe, pues, la frontera también como límite 
psicológico, trastorno de la personalidad, borderline, enfermedad mental, a veces, causada por la droga. Y es que la frontera entre la cordura y la locura, entre lo real y lo ficticio, el equilibrio y el trastorno, lo saludable y lo paranoico, depende en buena medida de trabajos mecánicos y rutinarios como es el de las maquilas; donde el ser humano encuentra sus límites emocionales y hasta cívicos. La historia se imbrica en la poesía para ver en todos los lugares un problema que no sólo se da en la frontera México-EUA: "Lo histórico, entonces, en la época telefísica es intercambiado por lo pantópico, sin que este reemplazo implique violencia o paradigma transgredido sino batuta entregada, estafeta indispensable: lo pantópico es histórico sin la necesidad de lo paulatino, sin el requisito de lo uno después de lo otro" (Yépez 2008b: 18-19). La metafísica se preocupó por lo inalcanzable y la "telefísica" nos muestra esa misma lejanía a través de formas (y ahora tecnologías) que nos la hacen ver cercana: "una manera de convertir la existencia en mirar lo más distante como si fuera lo más cercano y mirar lo más cercano como si no fuese verdad" (27).

Dicha teoría, en la que nos detenemos ahora para explicar la ligazón entre Yépez y García, ya inauguraba el tercer milenio con el libro Por una poética antes del paleolítico y después de la propaganda. Así lo sentenciaba el tijuanense: "EL úNICO / poder / que le está / reservado / al hombre / del tercer mundo / es el control / remoto / del televisor / importado" (2000: 40). La Tercera Nación de la ciudad fronteriza sería un invento para unir mundos, culturas e identidades (quizá la televisión también): "tenían antenas / a las que veneran / más de lo que los indios / veneran a sus dioses" (50). Cuando se diluye y se transforma el concepto de patria (Higashi 2017), cuando crece la identidad, la cultura, más allá de las fronteras, "Volver es un contrasentido" (Yépez 2000: 46). Y allende lo tecnológico, el declarado post-mexicano reivindica el papel de la mujer atendiendo, como García, al feminicidio: "una mujer encuerada / o mejor dicho / despellejada / violada hasta por los ojos / con las uñas estrelladas" (56); ya que una de las máximas que conforman la serie homónima del primer libro de Yépez es: "164. La fuerza femenina es el principio creador del universo; sin una vuelta y recreación de las diversas filosofías del principio femenino no hay futuro para la poesía. Ni para el mundo. El futuro es uterino" (90). Urge un cambio. La situación es absurda. Dice García en la serie 
que da nombre a Sicarii: "En casa / sentado en el sofá frente a la T.V / un hombre sin cabeza / mira en la televisión / la escena circular de su propia muerte" (2014a: 48). La televisión y el ordenador, en un pequeño hueco, acaban de fusionar un mundo en fisión. La sociedad tiene como objetivo lograr una imagen bella de sí misma, aunque sea artificial, contraria a la que genera la violencia, el paso del tiempo o los conflictos entre vecinos y vecinas. El poder de lo visual recupera una especie de caligrama a base de preguntas retóricas que podría simbolizar (Ábrego 2011) el enredo de una línea fronteriza (72) o láminas basadas en el test de Rorschach que la propia García incorpora en la serie "Intermedio" (73-82) para ver los cruces con el subconsciente. Tanto en Sicarii como en Bitácora de mujeres extrañas se ponen en cuestión los límites estéticos, específicamente, de la mujer que advertimos en La doncella negra y su poema "[Paraíso artificial]", donde se nos reclama que compremos "las tetas de silicona más caras / [...] soñando que es una modelo o estrella de cine / entre estas cerezas podridas del nuevo sueño gringo / [...] No pienses, / la televisión y el YouPorn / lo harán por ti / y gratuitamente te harán famos@ / en esta nuez podrida" (2010: 70). Somos pollos sin cabeza conducidos por polleros. La realidad natural de las vacas que amamantan a sus crías chocará con las tetas operadas de quienes buscan la fantasía como "Plastic Cows": "Ser de plástico ha resultado maravilloso / porque la matriz de la televisión en donde viven suspendidas / les regala un dulce y volátil sueño / el ser mujeres perfectas" (García 2014b: 78). Dicha retahíla de contrastes en la sociedad contemporánea, como granja, podría dialogar con Kilimanjaro (2011) de Maricela Guerrero (Ciudad de México, 1977), pues las imágenes surreales de la vaca coinciden en ambas poéticas de la frontera de México con euA o con el mismo México.

De nuevo en La doncella negra, en "Lugares para habitar", el poema "[Caja de cartón]" (2010: 64) ilustra la relación de la poesía con la imagen, con lo reciclable y con las carencias de la habitabilidad urbana en las áreas más pobres. El hecho de que este poemario se publique en la editorial Regia Cartonera, aprovechando cajas de cartón para darles nueva vida en libros de bajo coste y comprometidos con el medio ambiente, da un nuevo sentido a los límites del poema. En García la frontera no protagoniza en sí sus poemarios, pero sí la violencia que de ésta, en sus 
múltiples aristas, se genera. Aunque su primer libro puede leerse como novela, será en la hibridez de los géneros literarios, en Las tijeras de Átropos (2011), con la narrativa y la ficción, al igual que Yépez, cuando la juarense desarrolle la decadencia y la "telefísica" de la sociedad, de su entorno. Asimismo, tales temas confluyen en los poemas que la propia autora selecciona para su antología La piel del animal acorralado (2014). Por estos años, Yépez ya manifiesta su despedida de la poesía, al menos en español.

Sicarii ([2013] 2014), luego de varias presentaciones de quienes gobiernan en Saltillo, y de un aviso por parte de la autora de que el libro plasma la realidad decadente de México, se abre con la nota de un niño sicario que fue detenido entre EUA y México. Nació en San Diego y fue a vivir a México con la abuela: "Historias sobre un 'niño sicario' empezaron a difundirse a finales de 2010 tras la aparición en YouTube de un video en el que varios adolescentes posaban para la cámara al lado de cadáveres y armas" (2014a: 11). Como periodista, la poeta recoge los testimonios de quienes protagonizan sus poemas, con un hilo narrativo de nuevo sólido. Extiende así los límites de los sujetos de enunciación, dando voz a agentes y pacientes de la violencia, como hizo Sara Uribe (Querétaro, 1978) en Antígona González (2012). Los datos coinciden con los de la nota periodística que García adjuntaba al inicio del libro. El que podría ser el hijo de la autora, según los créditos finales (92), aparece en una imagen, Ilorando, en blanco y negro. Al igual que en el caso que vimos de Yépez, es fundamental el pie de foto. Este es el final del discurso que acompaña a la impactante fotografía (33):

Soy un gansta de la frontera haciendo bling bling mientras cerceno el brazo de mi enemigo l'am nothing l'am a pure mexican withetrash Soy el demonio la Santa Muerte Soy la gran bestia lo bárbaro lo salvaje Yo soy el que destruirá tu vida el país el mundo porque yo soy el jefe de jefes, señores: el niño sicario y nada ni nadie podrá conmigo (35).

El epígrafe del apartado que da título al poemario recuerda cómo Pacheco ya auguraba casos como este: "Ahora son hombres los niños que vivían de las ratas. / Actúan como sicarios de un poder invisible / y poco a poco pero noche tras noche / nos eliminan sin clemencia" (733). Algunas 
escenas resultan repetitivas y, a lo largo de la poética de García, desde sus primeros poemarios, sobresalen ideas, versos e imágenes que explican la cruda evolución de la metafísica a la "telefísica". Finalmente, "Abecedario de la muerte" termina con una ristra de personajes como Wendy: "W es por Wendy quien al salir temprano para ir a la escuela será levantada para luego ser encontrada, días después, en las afueras de la ciudad con una nota: 'Esto le va a pasar a tod@s aquell@s que quieran pasarse de la raya'" (2014a: 87). Sicarii muestra la experiencia personal de la poeta a través de distintos sujetos poéticos que despliegan en el poema las formas y los márgenes de la psicología que pueden asociarse con la frontera a través de la violencia infantil. "Al calor de la frontera nace el chicano, repudio de ambas partes: El chicano para la mente mexicana central es un culero vendido. Ellos sí que son los hijos de Malinche. No estamos espantados de perder la lengua madre (eso nos vale pura verga), sino de hacernos como los 'pochos'" (Yépez 2006: 55). Pochos — "Referido a un mexicano, que adopta costumbres o modales de los estadounidenses" (Company: 476)— será el término que de manera peyorativa recibe el protagonista de Sicarii (García 2014a: 24), el Ponchis, que efectivamente fue detenido en 2013.

En la entrevista que Esther M. García concedió a Zel Cabrera en Metrópoli Ficción (2017), asociando los límites con la maternidad, podemos ver cómo influyen en su obra poética los condicionantes de las fronteras espaciales, temporales y en cuanto a géneros literarios. Los animales, especialmente insectos, irán conformando la imagen de la madre (que también acaba siendo la propia poeta como autobiografía) y su relación con los tipos de fronteras que deben superar las víctimas de los feminicidios del norte. Bitácora de mujeres extrañas (2014) comienza con una serie llamada "Breviario de mujeres"; este es el primer poema, "Mujer Maquila":

Alina Orozco Gutiérrez

(Ciudad Juárez, Chih. 1954-El Paso, Txs. 2008)

La tristeza es un animal muy grande que se asoma en los ojos de ella

mientras fuma en silencio

un Marlboro rojo y espera a que suene la campana que anuncia el tercer turno 
$[\ldots]$

La cara es un mapa surcado

de vivir

de los pagos por hacer

de los turnos por cumplir

Para ella el sonido de la maquinaria

se convirtió en su música preferida

Las historias de las demás operarias

a la hora de la comida

son su novela favorita

Para ella ya no hay Dios

Todo es Deus ex machina

Vive esperando por la vuelta de tuerca

(un pequeño cáncer aflorándole en el pulmón)

mientras sigue fumando sigue esperando que suene la campana para comenzar a empaquetar (2014b: 11-12)

Una tercera persona se fija y describe la situación de una trabajadora que fuma durante el escaso tiempo de descanso en la fábrica. En su rostro aparece la sombra de ese animal que es la tristeza, la preocupación por sus cinco retoños. Aquí García no nos transmite la simpatía de Charles Chaplin en Tiempos modernos (1936) que sí dejaba ver el sarcasmo de Yépez. Apenas algún juego de palabras ilumina la escena. Tan lejos de Dios: "Para ella ya no hay Dios / Todo es Deus ex machina". La situación es real, no se puede resolver con la ficción. Ahora el gris es casi negro. Hay una "vuelta de tuerca" más, poco significativa (entre paréntesis): un cáncer. La campana le avisará del regreso al trabajo mecánico y frío donde ya tendrá más difícil ordenar sus pensamientos, su vida. Es un lugar común, pero la poeta lo personaliza incluyendo el nombre y los datos de nacimiento al principio de cada retrato. De esta manera conocemos a personajes que existieron y murieron; algunas todavía no, pero ya saben: el año en que lo harán o dejarán de hacerlo, "Ana Garza Fernández / (Cd. Camargo, Chih., 1979-Parras de la Fuente, Coah., 2030)" (13); el municipio, "Sarah Sevigny Ordóñez / (Casas Grandes, Chih., 1949-Eagle Pass, Txs., 2009)" (15); la frontera transexual (otra madre patria), "Diana Alelí Díaz antes José Daniel 
Jiménez / (Saltillo, Coah., 1978-Acuña, Coah.)" (27). Difícilmente podrán salir de ese espacio recluso. Como en la siguiente serie del poemario, "La embarazada solitaria", la familia (la madre o la hija que engendramos) no impide que de manera recíproca sigas estando sola en "Mujer solitaria cuidando a su madre" (17). A la manera de Saturno, "Mujer devorando al hijo" (22) marca la metamorfosis que ofrece definitivamente Mamá es un animal negro que va de largo por las alcobas blancas (2017): frontera entre la locura y la cordura de la realidad-ficción. Como vemos, es en el origen de las poéticas de Yépez y de García, y básicamente en el inicio de sus libros, donde se propone la frontera en sus distintas variantes. La primera sección del XI Premio Internacional de Poesía Gilberto Owen Estrada es "Tarantismo (Episodios histéricos)" y visibiliza el problema de mujeres que mataron a sus hijos por estar jugando, ellas, a la famosa "Farmerville en Facebook" (25). A continuación, en otras partes del poemario, distintas pero no tan distantes, clasifican y diagnostican los tipos de aborto: dos territorios se distancian a la fuerza. En "Tracey Emin dibuja arañas" la televisión separa a una pareja del aborto que ella acaba de tener, aunque nunca lo consideró suyo: "Mi cuerpo no es mío / está dentro de la tele / dentro de ese video". La locución prepositiva "dentro de" es la marca de la "telefísica", cómo vemos la frontera de México-EUA. La industria pornográfica, igual que la de las maquilas, nos muestra de cerca un mercado que nos aleja.

Esther M. García reflexiona en su obra sobre las redes sociales y su influencia en el devenir literario, crítico y social. Denunció en tiempo real el feminicidio al que sobrevivió en 2017 y se acercó a los y las más jóvenes con el Premio Nacional de Literatura para Jóvenes FeNaL-Norma 2018 por Confesiones de una booktuber. Quizá la figura materna dialogue con la paterna en su próximo poemario, La destrucción del padre.

\section{Conclusiones}

Heriberto Yépez y Esther M. García, aparentemente disímiles, tienen en común varios aspectos vinculados con la frontera, desde Tijuana, Ciudad Juárez y, posteriormente, Saltillo, San Diego o El Paso. En sus obras muestran el compromiso ecocrítico, la ironía, el desdoblamiento y la reflexión 
de lo que Yépez llama "telefísica" (esa imagen que el ser humano, de México concretamente, busca de acuerdo al capitalismo estadounidense). A través de uno de los máximos estudiosos de la frontera de México y EUA es posible entender casos particulares de la poesía mexicana contemporánea que confirman la hibridez (no de las ciudades fronterizas pero sí de los géneros literarios), la "telefísica" (en la preponderancia de lo visual) y la fisión (choque, a veces enriquecedor, de culturas que mantienen idiosincrasias definidas y delimitadas). Tales conceptos del tijuanense se pueden aplicar a la poeta de Saltillo.

Heriberto Yépez defiende la identidad mexicana que colinda con EUA y reivindica la convivencia manifestando una atrevida e innovadora poética que en el siglo Xxı se vale del ensayo, el habla coloquial, la filosofía, la política y la imagen histórica y actual de la ciudad donde nació, manifestando que "Il]a mejor literatura tijuanense es experimental" (2005a: 80). Por su parte, Esther M. García demuestra cómo, siendo también una escritora inicialmente al margen, por publicar en cartoneras y tratar conflictos de fuerte contenido autobiográfico, es posible establecer un contacto no sólo con el norte de México, sino con la cultura todavía centralizada que acapara la Ciudad de México. Los demás reconocimientos en su poesía, especialmente el Premio Nacional de Poesía Joven Francisco Cervantes Vidal en 2014 por Bitácora de mujeres extrañas le abrió un camino para escribir sobre la violencia en las fronteras, en las mujeres o en la sociedad del siglo xxı. En esta línea, Iveth Luna Flores recibió el mismo galardón dos años después por Comunidad terapéutica (2017). La joven regiomontana se formó en talleres poéticos de Saltillo y dio voz a problemas que conlleva la frontera (en todas sus aristas de conflicto y maltrato). Posteriormente, Esther M. García recibió el XI Premio Internacional de Poesía Gilberto Owen Estrada por Mamá es un animal negro que va de largo por las alcobas blancas (2017), en la línea de la violencia de quienes se encuentran en los diversos tipos de frontera que hemos analizado: espacial, en contacto con EUA, pero también social, feminista, temporal o tradicional. Entre pobres y ricos, generalmente mexicanas y estadounidenses, entre hombres y mujeres, entre la sociedad civil y la militar ("ización" del país) y entre indígenas, Tijuana y Ciudad Juárez no sólo se oponen a San Diego o El Paso, a Estados Unidos, sino que en la paradójica relación fronteriza 
de ambas ciudades se alejan de EUA y de México al mismo tiempo. Yépez rompe esta frontera virtual liberando buena parte de su obra en las bases de datos electrónicas que permiten acceder, como con Esther M. García en Poesía Mexa, a lo que se publica últimamente en la poesía mexicana contemporánea. A través de diversas instituciones estatales, se impulsó un discurso común en la narrativa pero no tanto en la lírica que igualmente asentaron Jorge Humberto Chávez, Jesús Ramón Ibarra o Balam Rodrigo para recoger (en 2013, 2015 y 2018, respectivamente) el premio más importante de poesía en México, el Aguascalientes, por obras que se fijan en las fronteras de México y que proyectan una obra conjunta, más allá del poema autónomo y particular. Se mantiene de este modo la conclusión a la que llegaba Jorge Aguilera al reseñar la obra de Jorge Humberto Chávez: "es probablemente una evidencia de que la poesía mexicana, al menos en una de sus vertientes más interesantes, ha retomado ese vínculo con los asuntos de interés público que en algún momento parecía haber perdido" (2013) y que desarrollará Israel Ramírez (2018). Poetas a ambos lados de la frontera de México y EUA evidencian los problemas que especialmente sufre el primero de los países. Con las Ilegadas de Donald Trump y Andrés Manuel López Obrador a los gobiernos de EUA y México, la poesía, a través de un discurso basado en la denuncia, el compromiso y lo coloquial, se centra en los límites para tratar de resolver, o al menos evidenciar, los tipos de violencia que la poesía empieza a mostrar en el tercer milenio.

Tanto Heriberto Yépez como Esther M. García logran, desde el margen o la periferia, focalizar la frontera y sus conflictos a partir de dos poéticas que más allá de sus diferencias tienen en común el compromiso por la fisión que se da en la falla entre México y EUA.

\section{Bibliografía}

Ábrego, Perla. "La frontera como sistema simbólico en la literatura mexicana contemporánea", en Revista Surco Sur, vol. 2, Iss. 3 (2011): 47-52. Artículo en línea disponible en: <http://scholarcommons.usf.edu/surcosur/vol2/iss3/15/> [consultado el 23 de agosto de 2018].

Aguilera LóPEZ, Jorge. "Te diría que fuéramos al río Bravo a llorar pero debes saber que ya no hay río ni llanto", en Periódico de Poesía. México: Universidad Nacional Autónoma de México, 62 (septiembre 2013). Artículo en línea disponible en: <http://www.periodicodepoesia.unam.mx/index.php/resenasec/51- 
resenas/2927-062-resenas-te-diria-que-fueramos-al-rio-bravo > [consultado el 16 de agosto de 2018].

Alemany Bay, Carmen. Artes poéticas mexicanas (de los Contemporáneos a la actualidad). Guadalajara: Centro Universitario de Ciencias Sociales y Humanidades / Universidad de Guadalajara, 2015.

Ángel, Diana Del. Procesos de la noche. México: Almadía, 2017.

AnZaldúA, GloriA. Borderlands / La Frontera [1987]. Trad. Carmen Valle. Madrid: Capitán Swing, 2016.

Arenas Monreal, Rogelio. "Espacio urbano y construcción de identidad: Instrucciones para cruzar la frontera (tensión Tijuana San Diego) en la narrativa de Luis Humberto Crosthwaite", en Cahiers d'Études Romanes, 12 (2005): 97-110. Artículo en línea disponible en: <https://etudesromanes.revues. org/2560\#quotation> [consultado el 14 de agosto de 2018].

Aridjis, Homero. Diario de sueños. México: Fondo de Cultura Económica, 2011.

Aura, Alejandro. Poemas y otros poemas. México: Fondo de Cultura Económica, 2003.

Baeza Munita, Francisca. Imaginario urbano fronterizo y resistencia cultural en Mapurbe de David Aniñir y Por una poética antes del paleolítico y después de la propaganda de Heriberto Yépez. Valparaíso: Pontificia Universidad Católica de Valparaíso, 2012.

Ballester, Ignacio y Alejandro Higashi. "Tachaduras y borraduras en la poesía mexicana contemporánea (Albarrán, Herbert, Alcantar)", en Signos Literarios. México: Universidad Autónoma Metropolitana, vol. XIII, 25 (2017): 8-43. Artículo en línea disponible en: <http://signosliterarios.izt.uam.mx/index.php/ SLIT/issue/view/109> [consultado el 21 de febrero de 2018].

Ballester, Ignacio. "Ciudad de México en José Emilio Pacheco y Homero Aridjis: la poesía ecológica", en Benito García Valero y Carlos Hernández Carrión (eds.). Magia, irracionalismo y visión ecocrítica de la ciudad. Valladolid: Universitas Castellae, 2018a. 191-210 (Colección "Cultura Iberoamericana", 41). Artículo en línea disponible en: <https://www.academia.edu/37201528/Ciudad_de_M\%C3\%A9xico_en_Jos\%C3\%A9_Emilio_Pacheco_y_Homero_Aridjis_la_poes\%C3\%ADa_ecol\%C3\%B3gica> [consultado el 25 de agosto de 2018].

Ballester, IgnaCio. "Tabla sin asidero: el feminismo en la poesía mexicana actual a través de Dolores Dorantes", en Mitologías Hoy. Friedhelm Schmidt-WeIle e Irma Bañuelos Ávila (coords.). Género, educación y nación en México (1810-1950). Pedagogías, poses e ideales sexoculturales. Barcelona: Universitat Autònoma de Barcelona, vol. 18 (diciembre de 2018b): 207-223. Artículo en línea disponible en: <https://revistes.uab.cat/mitologias/issue/view/28/ showToc $>$ [consultado el 8 de enero de 2019].

BALleSter, IGNACIO. "La evolución formal de la poesía mexicana en torno a Heriberto Yépez y el espacio urbano: Por una poética antes del paleolítico y después de la propaganda" [en prensa].

Belausteguigoitia, Marisa. "Borderlands / La Frontera: el feminismo chicano de Gloria Anzaldúa desde las fronteras geoculturales, disciplinarias y pedagógicas", en Debate Feminista. México: Centro de Investigaciones y Estudios 
de Género de la Universidad Nacional Autónoma de México, vol. 40 (octubre de 2009): 149-169. Artículo en línea disponible en: <https://www.jstor. org/stable/42625120?seq=1\#page_scan_tab_contents $>$ [consultado el 27 de agosto de 2018].

Benjamin, Walter. Imaginación y sociedad. Iluminaciones I [1969]. Prólogo y traducción de Jesús Aguirre. Madrid: Taurus, 1990.

Bustamante, Jorge A. "Frontera México-Estados Unidos: reflexiones para un marco teórico", en Frontera Norte. Revista internacional de fronteras, territorios y regiones / International Journal of Borders, Territories and Regions. Tijuana: El Colegio de la Frontera Norte, vol. 1-1 (enero-junio de 1989): 8-24. Artículo en línea disponible en: <https://fronteranorte.colef.mx/index.php/fronteranorte/ article/view/1666> [consultado el 25 de agosto de 2018].

Cabrera, Zel. "La crudeza como poética personal", entrevista a Esther M. García, en Metrópoli Ficción. México (1 de agosto de 2017). En línea disponible en: $<$ http://metropolifixion.com/la-crudeza-como-poetica-personal/> [consultado el 24 de agosto de 2018].

CAStillo, RAmÓN. "Brevísima y veloz presentación del peatonauta", en Casa del Tiempo, 8 (2014): 31-33. Artículo en línea disponible en: <http://www.uam.mx/ difusion/casadeltiempo/08_sep_2014/casa_del_tiempo_eV_num_8_31_33. pdf $>$ [consultado el 27 de febrero de 2016].

Cerón, Rocío. Enclave. Poéticas experimentales. México: EBL-Intersticios, 2015.

Cerón, Rocío. Verbo Vortex. Laboratorio de Poesía Expandida. México: Universidad Nacional Autónoma de México, 2016. En línea disponible en: <http:// ec.filos.unam.mx/2015/09/02/verbo-vortex-laboratorio-de-poesia-expandi$\mathrm{da} />$ [consultado el 16 de agosto de 2018].

Chávez, Jorge Humberto. Te diría que fuéramos al río Bravo a llorar pero debes saber que ya no hay río ni llanto. México: Fondo de Cultura Económica / Consejo Nacional para la Cultura y las Artes / Instituto Cultural de Aguascalientes / Instituto Nacional de Bellas Artes, 2013.

COMPAny, Concepción (coord.). Diccionario de mexicanismos. México: Siglo XXI, 2010. Disponible en: <https://www.academia.org.mx/obras/obras-de-consulta-en-linea/diccionario-de-mexicanismos $>$ [consultado el 16 de agosto de 2018].

CrosthwaIte, Luis Humberto. Instrucciones para cruzar la frontera [2002]. México: Tusquets, 2011.

Díaz Perucho, Javier. Estéticas de los confines. Expresiones culturales en la frontera norte. México: Verdehalago, 2004.

Domínguez Michael, Christopher. "El imperio de la neomemoria y Al otro lado, de Heriberto Yépez", en Letras Libres (31 de agosto de 2009). Artículo en línea disponible en: <https://www.letraslibres.com/mexico/libros/el-imperiola-neomemoria-y-al-otro-lado-heriberto-yepez> [consultado el 14 de agosto de 2018].

Dorantes, Dolores. Estilo. Guadalajara: Mano Santa Editores, 2011. Disponible en: <https://issuu.com/luisfernandoortega/docs/dolores_dorantes> [consultado el 27 de agosto de 2018]. 
García, Esther M. La doncella negra. Monterrey: Regia Cartonera, 2010. Disponible en: <https://poesiamexa.wordpress.com/2016/04/02/esther-m-garcia/> [consultado el 14 de agosto de 2018].

García, Esther M. Las tijeras de Átropos. Saltillo: Universidad Autónoma de Coahuila, 2011.

García, Esther M. Sicarii [2013]. Saltillo: Instituto Municipal de Cultura de Saltillo, 2014a. En línea disponible en: <https://poesiamexa.wordpress. com/2016/04/02/esther-m-garcia/> [consultado el 14 de agosto de 2018].

García, Esther M. Bitácora de mujeres extrañas. México: Consejo Nacional para la Cultura y las Artes, 2014b.

García, Esther M. La piel del animal acorralado. Antología personal. Coahuila: Gobierno de Coahuila / Consejo Nacional para la Cultura y las Artes, 2014c. Disponible en: <https://issuu.com/edicionesseccoahuila/docs/la_piel_del_animal_acorralado_-_est> [consultado el 24 de agosto de 2018].

García, Esther M. Mamá es un animal negro que va de largo por las alcobas blancas. Toluca: Universidad Autónoma del Estado de México, 2017. Disponible en: <http://ri.uaemex.mx/handle/20.500.11799/67447> [consultado el 28 de enero de 2018].

García, Esther M. Confesiones de una booktuber. México: Zona Libre, 2018.

García, Esther M. La destrucción del padre. Coahuila: Secretaría de Cultura del Estado de Coahuila de Zaragoza [en prensa].

García CANClini, Néstor. Culturas híbridas. Estrategias para entrar y salir de la modernidad. México: Grijalbo, 1989.

Guerrero, Maricela. Kilimanjaro. Guadalajara: Mano Santa, 2011. Disponible en: $<$ https://poesiamexa.wordpress.com/2016/03/19/maricela-guerrero/> [consultado el 26 de agosto de 2018].

Higashi, Alejandro. PM / XXI / 360 . Crematística y estética de la poesía mexicana contemporánea en la era de la tradición de la ruptura. México: Universidad Autónoma Metropolitana / Tirant Lo Blanch, 2015.

Higashi, Alejandro. "México, poesía y patria", en iMex (febrero de 2017). Artículo en línea disponible en: <https://www.imex-revista.com/xi-mexico-poesia-ypatria/> [consultado el 29 de noviembre de 2017].

IBARRA, Jesús Ramón. Teoría de las pérdidas. México: Fondo de Cultura Económica / Instituto Cultural de Aguascalientes / Instituto Nacional de Bellas Artes, 2015.

IRIS, MANuel. "Soy de aquí", en Tierra Adentro. México (6 de enero de 2017). Artículo en línea disponible en: <https://www.tierraadentro.cultura.gob.mx/soyde-aqui/> [consultado el 24 de agosto de 2018].

José Agustín. Tragicomedia mexicana 1. La vida en México de 1940 a 1970. México: Planeta, 1990.

Landau, Saul y Sonia Angulo. Maquila: A tale of two Mexicos (Maquila: Una historia de dos Méxicos). euA: California State Polytechnic University, Pomona / Rel-UITA, 2000. Disponible en: <http://www.cultureunplugged.com/ play/3527/Maquila--A-Tale-of-Two-Mexicos> [consultado el 18 de agosto de 2018]. 
Ledesma, Eduardo. Radycal Poetry. Aesthetics, Politics, Technology, and the IberoAmerican Avant-Gardes, 1900-2015. Albany: State University of New York Press, 2016.

Méndez, Eloy, Isabel Rodríguez y Liliana López. "El modelo actual de la ciudad fronteriza mexicana. Urbanismos yuxtapuestos y herméticos", en Bifurcaciones. Revista de Estudios Culturales Urbanos, 4 (2005): 1-14. Artículo en línea disponible en: <http://www.bifurcaciones.cl/004/bifurcaciones_004_MRL.pdf> [consultado el 27 de octubre de 2017].

Montezemolo, Fiamma. "Cómo dejó de ser Tijuana laboratorio de la posmodernidad / Diálogo con Néstor García Canclini" (entrevista realizada el 7 de septiembre de 2008), en Alteridades. México, vol. 19, 38 (julio-diciembre de 2009). Artículo en línea disponible en: <http://www.scielo.org.mx/scielo.php?script=sci_artte xt\&pid=S0188-70172009000200010 > [consultado el 23 de agosto de 2018]

Moraña, Mabel (ed.). Cultura y cambio social en América Latina. Madrid: Iberoamericana / Vervuert, 2008.

Pablo, ÓsCar DE. El baile de las condiciones. México: Consejo Nacional para la Cultura y las Artes, 2011.

Pablo, Óscar De. De la materia en forma de sonido. México: Instituto Literario de Veracruz / Consejo Nacional para la Cultura y las Artes, 2015.

PACHeCO, José EMILIO. Tarde o temprano [Poemas 1958-2009]. Barcelona: Tusquets, 2010.

PalAVersich, Diana. "La ciudad que recorro. Un flâneur en Tijuana", en Literatura Mexicana, XIII-2 (2002): 215-227. Artículo en línea disponible en: <https:// revistas-filologicas.unam.mx/literatura-mexicana/index.php/lm/article/ view/429/428> [consultado el 27 de octubre de 2017].

Palaversich, Diana. "Ciudades invisibles. Tijuana en la obra de Federico Campbell, Luis Humberto Crosthwaite, Francisco Morales y Heriberto Yépez", en Iberoamericana, vol. XII-46 (2012): 99-110. Artículo en línea disponible en: <https://journals.iai.spk-berlin.de/index.php/iberoamericana/article/ view/490> [consultado el 22 de agosto de 2018].

Pimienta, Omar. La Libertad: ciudad de paso. Tijuana: Consejo Nacional para la Cultura y las Artes, 2006. Disponible en: <https://poesiamexa.wordpress. com/2016/06/08/omar-pimienta/> [consultado el 19 de octubre de 2017].

Quirarte, Vicente. Vergüenza de los héroes. Armas y letras de la guerra entre México y Estados Unidos. México: Umbral, 1999.

Ramírez CRUZ, ISRAEl. "La poesía, una periferia en la llamada literatura del norte: de José de Jesús Sampedro a Jorge Humberto Chávez", en Coloquio 50 años del Premio Bellas Artes de Poesía Aguascalientes. Centro de Investigación y Estudios Literarios de Aguascalientes CIELA Fraguas, 2 de mayo de 2018.

Ramírez Vuelvas, Carlos. Los Contradioses. Tijuana: Ayuntamiento de Tijuana. Instituto Municipal de Arte y Cultura, 2015.

Real Academia Española. Diccionario de la lengua española (23a ed.), 2014. Disponible en: <http://www.rae.es/> [consultado el 25 de agosto de 2018].

Revel Mouroz, Jean. "La frontera México-Estados Unidos: mexicanización e internacionalización", en Estudios Fronterizos, año II, vol. I, 4-5 (mayo-agosto y septiembre-diciembre de 1984): 11-29 Artículo en línea disponible en: 
<http://ref.uabc.mx/ojs/index.php/ref/article/viewFile/380/606> [consultado el 16 de agosto de 2018].

Rodrigo, Balam. Marabunta. México: Consejo Estatal para la Cultura y las Artes de Nayarit (CECAN) / Libros Invisibles, 2017.

Rodrigo, Balam. Libro centroamericano de los muertos. México: Fondo de Cultura Económica / Instituto Cultural de Aguascalientes / Instituto Nacional de Bellas Artes, 2018.

Ruzzi, SilviA. "Al otro lado de Heriberto Yépez. Percepciones desde y sobre la frontera México-Estados Unidos", en ACT 29 - Literaturas e Culturas em Portugal e na América Hispânica - Novas Perspectivas em Diálogo. Lisboa: Húmues / Centro de Estudos Comparatistas, 2014. 109-120. Artículo en línea disponible en: <https://www.academia.edu/26741847/AL_OTRO_LADO_ DE_HERIBERTO_Y\%C3\%89PEZ._PERCEPCIONES_DESDE_Y_SOBRE_LA_ FRONTERA_M\%C3\%89XICO__ESTADOS_UNIDOS> [consultado el 22 de agosto de 2018].

SAAVEDRA, RAfael. "Blogs y literatura: una post-conversación e intervención ensayística", en Border Pop: texturas, interferencias y diálogos. Mexicali: Instituto de Cultura de Baja California, 2012. 86-111. Artículo en línea disponible en: <https://www. academia.edu/17591067/_Blogs_y_literatura_una_post-conversaci\%C3\%B3n_e_ intervenci\%C3\%B3n_ensay\%C3\%ADstica_Tijuana_2002-2009_> [consultado el 22 de agosto de 2018].

SÁnChez MARtín, Eva. "Feminicidio y maquila en Ciudad Juárez", en Revista d'Estudis de la Violència, 2 (abril de 2007). Artículo en línea disponible en: $<$ https://artecontraviolenciadegenero.org/?wpfb_dl=1> [consultado el 18 de agosto de 2018].

Stabile, Uberto (coord.). Tan lejos de Dios. Poesía mexicana en la frontera norte. México: Baile del Sol / Universidad Nacional Autónoma de México, 2010.

Uribe, Sara. Antígona González. México: Surt, 2012. Disponible en: <https:// poesiamexa.wordpress.com/tag/sara-uribe/> [consultado el 26 de febrero de 2017].

Valenzuela ArCe, José Manuel. "Desplazamientos y fronteras: representaciones fronterizas y nuevos desafíos para América Latina", en Mabel de Pablo (ed.). Cultura y cambio social en América Latina. Madrid: Iberoamericana / Vervuert, 2008. 17-35.

Villoro, JuAn. "Nada que declarar. Welcome to Tijuana", en Letras Libres. "Vida en la frontera". México, 17 (mayo de 2000). Artículo en línea disponible en: $<$ https://www.letraslibres.com/mexico/revista/vida-en-la-frontera $>$ [consultado el 22 de agosto de 2018].

YéPEZ, Heriberto. Por una poética antes del paleolítico y después de la propaganda. Tijuana: Anortecer, 2000.

YéPeZ, Heriberto. El matasellos. México: Editorial Sudamericana, 2004.

Yépez, Heriberto. Made in Tijuana. Baja California: Gobierno del Estado de Baja California, 2005a. Disponible en: <https://es.scribd.com/document/72009710/ Heriberto-Yepez-Made-in-Tijuana> [consultado el 27 de octubre de 2017].

Yépez, Heriberto. "Prolegómenos a toda tijuanología del peor-venir", en Letras Libres (2005b). Artículo en línea disponible en: <http://www.letraslibres.com/ 
mexico/prolegomenos-toda-tijuanologia-del-peor-venir> [consultado el 27 de octubre de 2017].

Yépez, Heriberto. A.B.U.R.T.O. México: Editorial Sudamericana, 2005c. Disponible en: <https://es.scribd.com/document/214072807/A-B-U-R-T-O-HeribertoYepez> [consultado el 14 de agosto de 2018].

Yépez, Heriberto. Tijuanologías. México: Libros del Umbral / Universidad Autónoma de Baja California, 2006. Disponible en: <https://www.academia. edu/18125871/TIJUANOLOGIAS_1999-2006_> [consultado el 21 de agosto de 2018].

YéPeZ, HeRIBerto. El imperio de la neomemoria. México: Almadía, 2007a. Disponible en: <https://es.scribd.com/document/212729354/Heriberto-Yepez> [consultado el 21 de agosto de 2018].

Yépez, Heriberto. "La frontera como falla", en Metapolítica. Vivir al filo. Fracturas. Fisuras. Fronteras, vol. 11-52 (marzo-abril de 2007b). Artículo en línea disponible en: <https://www.academia.edu/18833389/_La_Frontera_como_FaIla_2007_> [consultado el 21 de agosto de 2018].

Yépez, Heriberto. El órgano de la risa. México: Aldus / Consejo Nacional para la Cultura y las Artes, 2008a. Disponible en: <https://es.scribd.com/document/89560600/El-organo-de-la-risa-Heriberto-Yepez> [consultado el 17 de agosto de 2018].

Yépez, Heriberto. Contra la Tele-visión: un ensayo antiestelar. México: Tumbona Ediciones, 2008b.

Yépez, Heriberto. Al otro lado. México: Planeta, 2008c.

Yépez, Heriberto. El libro de lo Post-Poético. Mexicali: Instituto de Cultura de Baja California / Consejo Nacional para la Cultura y las Artes, 2012a. Disponible en: <https://www.academia.edu/18126133/EL_LIBRO_DE_LO_POST-POETICO_2008-2012_> [consultado el 17 de agosto de 2018].

YéPEZ, Heriberto. "Lo post-transfronterizo" [2010], en Literal: Latin American Voices, 21 (2012b): 26-28. Artículo en línea disponible en: <http://literalmagazine.com/lo-post-transfronterizo/> [consultado el 22 de agosto de 2018].

YéPeZ, Heriberto. "Entrevista sobre la literatura de Tijuana y fronteriza", en Édgar Cota Torres y José Salvador Ruiz Méndez (coords.). En voz propia. In ther own voices. Entrevistas con narradores de la frontera México-Estados Unidos. México: Editorial Artificios / University of Colorado / Colorado Springs / Universidad Autónoma de Baja California, 2014. 253-264. Artículo en línea disponible en: <https://www.academia.edu/18786784/_Entrevista_sobre_la_ literatura_de_Tijuana_y_fronteriza_2014_> [consultado el 21 de agosto de 2018].

YÉPEZ, HeRIBERTO. (@haceyepez). Instagram. 31 de julio, 2017a. Disponible en: $<$ https://www.instagram.com/p/BXOIT02nD3V/?hl=es\&taken-by=hacheyepez> [consultado el 19 de octubre de 2017].

Yépez, Heriberto. Transnational Battle Field. United States: Commune Editions, $2017 \mathrm{~b}$.

Yépez, Heriberto. "Sobre Una Historia del Arte of Border Art", en Border Destroyer, 28 de abril, 2017c. Artículo en línea disponible en: <https://border- 
destroyer.com/2017/04/28/sobre-una-historia-del-arte-of-border-art/?framenonce $=$ f88d808666 $>$ [consultado el 21 de agosto de 2018] .

YépeZ, HeRIBERTO. "Descolonización y cultura. Teoría y praxis de los sures de la poética", en Border Destroyer, agosto, 2017d. Artículo en línea disponible en: $<$ https://borderdestroyer.com/2017/08/24/descolonizacion-y-cultura-teoria-ypraxis-desde-los-sures-de-la-poetica/> [consultado el 26 de agosto de 2018].

YéPEZ, Heriberto. "Teoría y taller de ensamblaje", en Border Destroyer, 21 de marzo, 2018a. Artículo en línea disponible en: <https://borderdestroyer. com/2018/03/21/teoria-y-taller-de-ensamblaje/> [consultado el 21 de agosto de 2018].

Yépez, Heriberto. "Nuevas Tijuanologías: del Hibridismo a las Rudologías en las estéticas fronterizas", en Revista Iberoamericana, vol. LXXXIV, 265 (octubrediciembre de 2018b): 975-993. Artículo en línea disponible en: <https:// www.academia.edu/38027434/Nuevas_Tijuanolog\%C3\%ADas_del_ Hibridismo_a_las_Rudolog\%C3\%ADas_en_las_est\%C3\%A9ticas_fronterizas_2018_> [consultado el 8 de enero de 2019].

Ignacio Ballester Pardo

Es doctor en Filosofía y Letras por la Universidad de Alicante. Es miembro del Seminario de Investigación en Poesía Mexicana Contemporánea, con sede en la Universidad Nacional Autónoma de México. Se ha especializado en la obra de Vicente Quirarte. Otras de sus líneas de investigación son la narrativa digital, a propósito de Margo Glantz, o la poesía experimental, junto a la Benemérita Universidad Autónoma de Puebla. Recientemente ha publicado "Tachaduras y borraduras en la poesía mexicana contemporánea (Albarrán, Herbert, Alcantar)" (2017), en el número 25 de Signos Literarios, en colaboración con Alejandro Higashi; con quien coordina el número 23 de la revista América sin Nombre, titulado "Madurez de la joven poesía mexicana" (2018). Al respecto reflexiona cada domingo en su blog "Poesía mexicana contemporánea". 